\title{
Nanotechnology Applications in Science and Technology
}

\author{
D.T. Sakhare \\ U.G., P.G. \& Research Centre, Department of Chemistry, \\ Shivaji Art's, Comm. \& Science College Kannad Dist. Aurangabad.431103 (M.S.) India \\ Email: sakharedhondiram@yahoo.com
}

\begin{abstract}
Nanotechnology is helping to considerably improve, even revolutionize, many technology and industry sectors: information technology, energy, environmental science, medicine, homeland security, food safety, and transportation, among many others. Today's nanotechnology harnesses current progress in chemistry, physics, materials science, and biotechnology to create novel materials that have unique properties because their structures are determined on the nanometer scale. This paper study the various applications of nanotechnology in recent decades. "Nanotechnology". It gives a brief description about Nanotechnology and its application in various field's viz. medicine, computing, Robotics, food technology and Solar cells etc. It also deals with the future perspectives of Nanotechnology. Nanotechnology is the study of minuscule particles. The nanotechnology imagines a world wherein new items are planned at the nuclear and atomic level; give sensible, savvy techniques for lashing sustainable power sources and keeping the climate clean.
\end{abstract}

Keywords: Nanoelectronics, Nanotubes, Nanomedicine, Nanofilms, Nanotechnology, Environmental Science, Agriculture, Food safety, Engineering.

\section{Introduction:}

Nanotechnology is the investigation of the controlling the matter on a particle and atomic scale. By and large nanotechnology manages structures estimated between 1-100 nanometers in something like one measurement, and include altering or creating materials inside that size. It makes the material lighter, more grounded, quicker, more modest and more tough.

Nanotechnology commits the capacity to outline parts of atomic size and exact machine. All in all, 'nanotechnology' alludes to the created capacity to develop things from the base up, utilizing apparatuses and procedures that are being characterized to make elite items. In 1959, a physicist R. Feynman imagined this hypothetical ability. As per National science Foundation, 
Nanotechnology is the ability to comprehend, control and control matter at the degree of individual iotas and atoms. Nanotechnology is the mechanical advancement of the $21^{\text {st }}$ century. Innovative works in this field are developing quickly all over the world. A significant commitment of this field is the improvement of new materials in the nanometer scale. These are typically particulate materials with something like one element of under 100 nanometers (nm), even the particles could be zero measurement on account of quantum dabs. Metal nanoparticles have been of extraordinary interest because of their unmistakable highlights, for example, reactant, optical, attractive and electrical properties. Nanoparticles display totally new or further developed properties with bigger particles of the mass materials, and these book properties are inferred because of the variety in explicit qualities like size, appropriation, and morphology of the particles[1].Science and designing are the essential administrators of worldwide innovative rivalry. Current science dependent on the bringing together elements of nature at the nano scale contributes another establishment for advancement, information, and reconciliation of innovation [1].Nanotechnology is some of the time proffered as a universally useful innovation in light of the fact that in its high level form it will altogether affect practically all spaces of society and all businesses [2]. There is a longitudinal course of union and disparity in broad spaces of designing and science. For instance the union of sciences at large scale was expected during the Renaissance, and it was hitherto trailed by restricted disciplinary specialization (NDS) in science and designing in the eighteenth nineteenth hundreds of years. The assembly at the nanoscale arrived at its muscle in with regards to year 2000, and an assessment of a difference in the nano framework structures in the following many years. The Figure.1 addresses how innovations combined to nano particles and how the nano world came to [3].

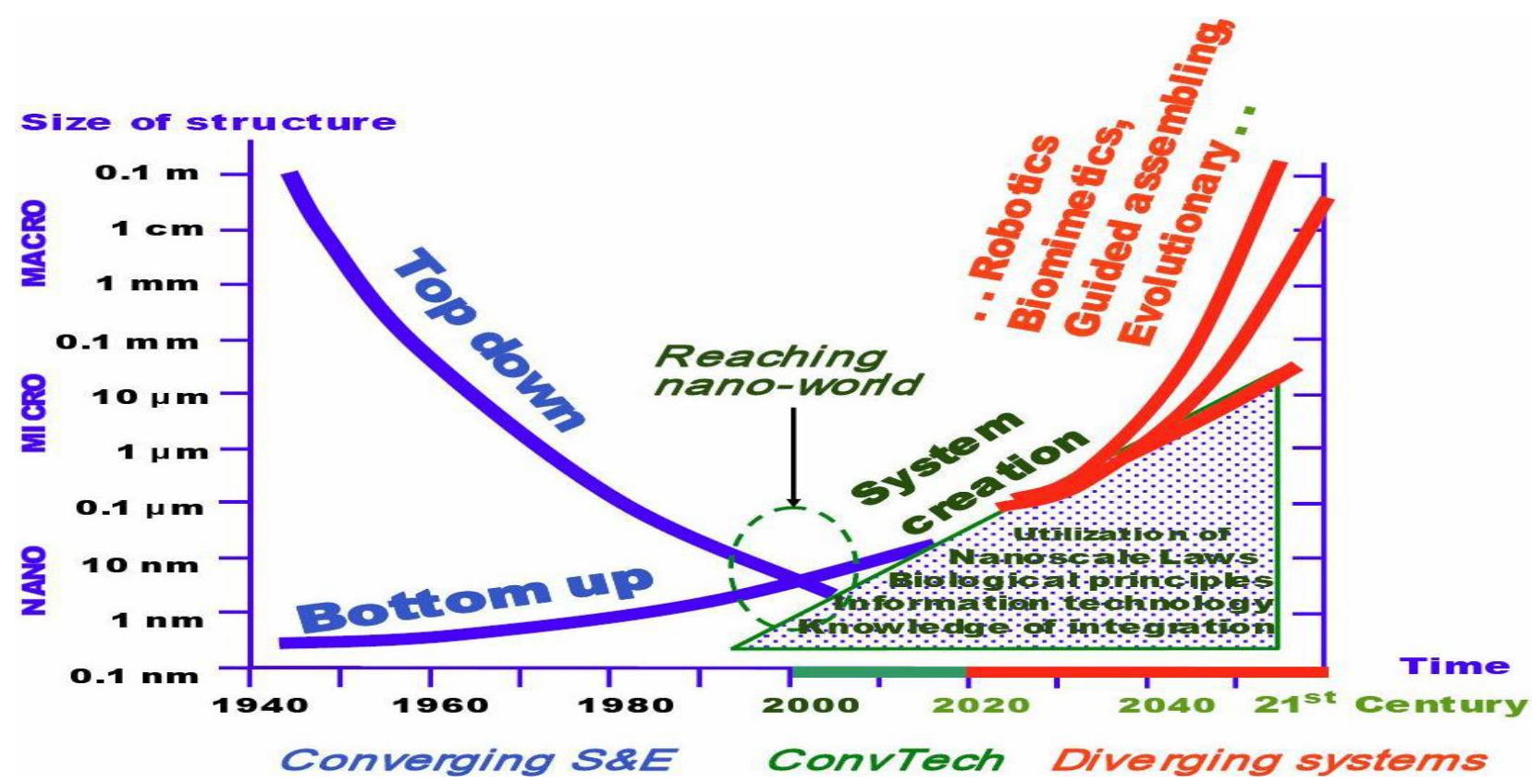

Fig.1. Reaching at the nanoworld (about 2000) and "converging technologies" approach for system creation from the nanoscale (2000-2020) towards new paradigms for nanosystem architectures in applications (after 2020). [3] 


\section{Branches of Nanotechnology:}

In this part, a concise outline is given with regards to the parts of nanotechnology. Various Nanotechnology items are accessible and still an imposing measure of explores are happening in research labs and colleges. Nanotechnology branches are being fostered that could bang the worldwide market for mineral, non-fuel items and agrarian. By and by, Nanotechnology is portrayed as progressive discipline as far as its impact on modern applications. Nanotechnology offers likely answers for a few issues utilizing exuding nano strategies. Contingent upon the solid entomb board character of nanotechnology there are a few exploration fields and different potential applications that includes nanotechnology. Here are a few branches where nanotechnology has been executed [4].

\subsection{Nano Engineering:}

Nano engineering is the branch nanotechnology practice on the nanoscale. The name 'Nanodesigning' is gotten from the nanometer, a unit of estimation rising to one billionth meters. This branch emphasizes the designing as opposed to the applied science part of the field. Examining burrowing magnifying lens (STM) and sub-atomic self-gathering are two strategies of Nano engineering.STM is utilized to utilize structures as little as a solitary iota while with Molecular self-get together, a discretionary grouping of DNA can orchestrated and used to make custom proteins or customary examples of amino acids [5].

\subsection{Green Nanotechnology:}

Green nanotechnology is the part of nanotechnology that improves the ecological manageability of cycles producing negative feature. It incorporates fabricating green Nano-items and afterward utilizing these Nano-items on the side of manageability [6]. The objective of green nanotechnology is to limit future natural and human wellbeing hazards related with the utilization of nanotechnology items, and to support the supplanting of existing items with nanoitems that are all the more harmless to the ecosystem. Sunlight based cells [7], Nano remediation and water treatment all applications depend on green nanotechnology [8].

\subsection{Wet Nanotechnology:}

Wet nanotechnology refers to working up with large masses from small ones [9]. W. Eric Drexler put forth the idea of Nano-assemblers working dry. The wet nanotechnology comes out to be the first area in which a Nano-assembler attains the trading results. Pharmaceuticals and bioscience are main features of wet nanotechnology [10]. R.A.L. Jones puts the bits of natural nanotechnology into a synthetic structure biokleptic nanotechnology. Using the guiding principles of biomimetic nanotechnology, trillions of nanotech robots are designed that resemble bacteria in structural properties, entering a person's blood stream to do medical treatments like cancer [11]. 


\section{Uses of Nanotechnology:}

From the beyond twenty years, researchers and architects have dominated the intricacies of working with nonmaterial and research is as yet continuing. These days a large portion of the items are made by nanoscale materials. Sunscreens containing nanoscale zinc Oxide or titanium dioxide that mirrors bright light to deflect burns from the sun. A nanoscale dry powder can kill gas. Along these lines, the nanoscale materials are being utilized to make the batteries for instruments to convey more force, all the more quickly and dispersing less hotness. The dressing of hostile to bacterial injury use nanoscale silver [11]. Different employments of nanotechnology incorporates athletic gear, vehicle parts, stockpiling of force in batteries, saturating viability of beauty care products, drug conveyance and other various methods and items dependent on nanoscale material are portrayed in abrupt.

\subsection{Carbon Nano Tubes (CNT):}

Carbon nanotubes are allotropes of carbon having a tube shaped nanostructure. Nanotubes have been built with length-to-distance across proportion of up to 2, 80, 00,000:1 that is a lot bigger than some other material. These tube shaped carbon atoms have remarkable strength and one of a kind electrical properties. These original properties make them significantly valuable in different applications in hardware, nanotechnology, optics, materials science, just as in design fields. Their last use, nonetheless, might be restricted by their potential poisonousness [11]. Nano tubes are displayed in Figure 2.

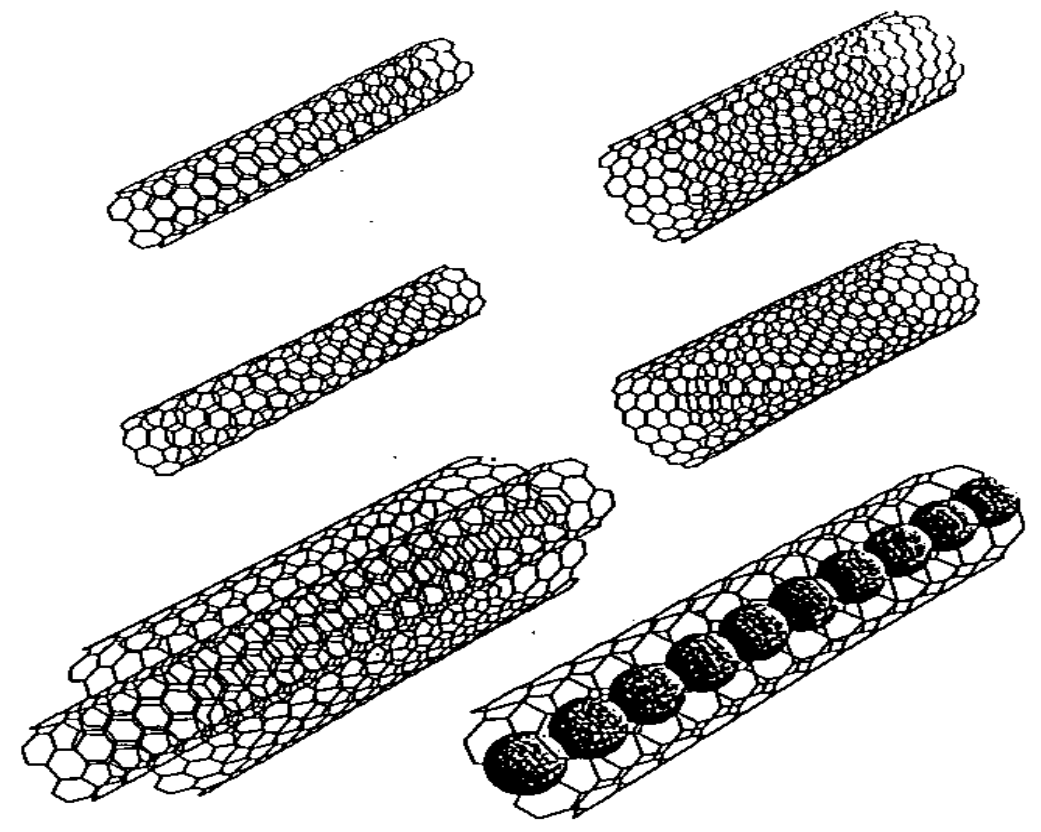

Fig.2. Carbon Nano Tubes (CNT) [11] 


\subsection{Thin Nano Films:}

Different nanoscale materials can be utilized in meager movies to make them water repellent, UV or IR-safe, against intelligent, hostile to microbial, self-cleaning, hostile to mist, Scratch safe or electrically conductive. Uses of Nano films incorporate PC show, cameras and eyeglasses [11]. Nano film is displayed in Figure 3.

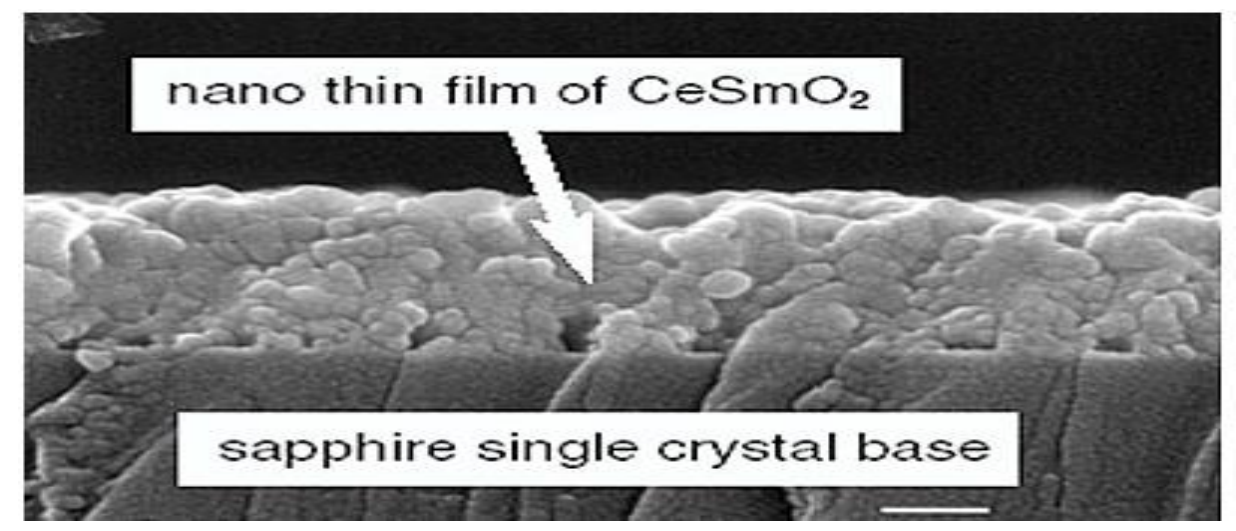

Fig.3. Thin Nano film [11]

\subsection{Nano scale Transistors:}

A semiconductor is a semiconductor electronic device used to amplify or switch electronic signals and electrical power. In semiconductors, a limited quantity of power is utilized as a door to control the progression of bigger measure of power. More the quantity of semiconductors are inserted in the PC, the more noteworthy will be power. Semiconductors sizes have been diminishing step by step, so PC have become all the more impressive. Upto now, the business' best exchanging innovation created CPUs with semiconductors having 45-nanometer highlights. Ongoing declarations show that much more little size of semiconductors is conceivable with the assistance of nanotechnology [12]. Nano scale semiconductors are displayed in Figure 4.

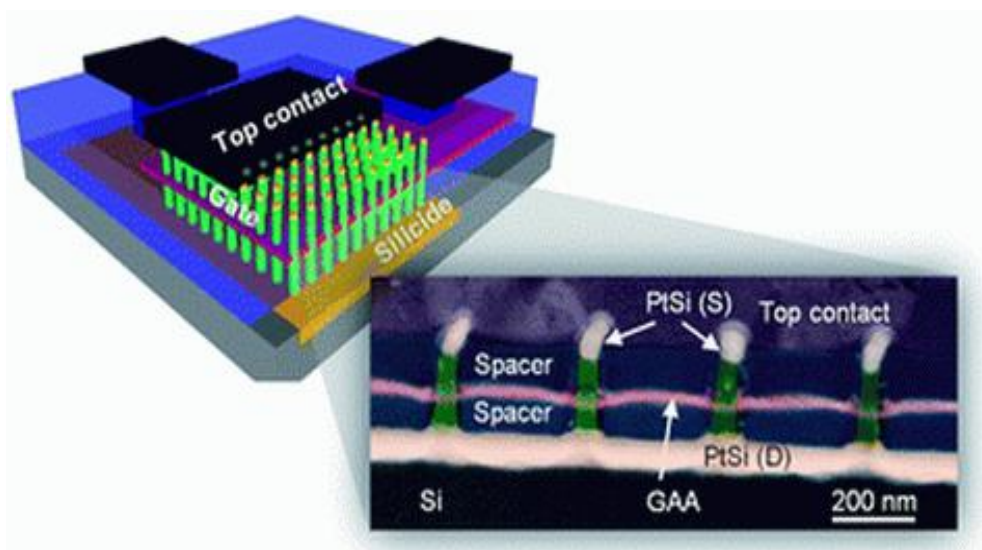

Fig.4. Nano scale Transistors [12] 


\subsection{Drug-Delivery Technique using Dendrimers:}

Dendrimers are exceptionally spread, star-formed macromolecules with nanometer-scale measurements displayed in Figure 5. Dendrimers are extraordinarily planned and produced for an immense assortment of utilizations, including the therapy of malignancy, drug conveyance, catalysis, quality reverie, and energy gathering and photograph action. Dendrimers conveying various materials and their branches can complete a few things all at once, for example, seeing unhealthy cells, diagnosing ailing states (counting cell demise), drug conveyance, depicting area and announcing occasions of treatment [11].
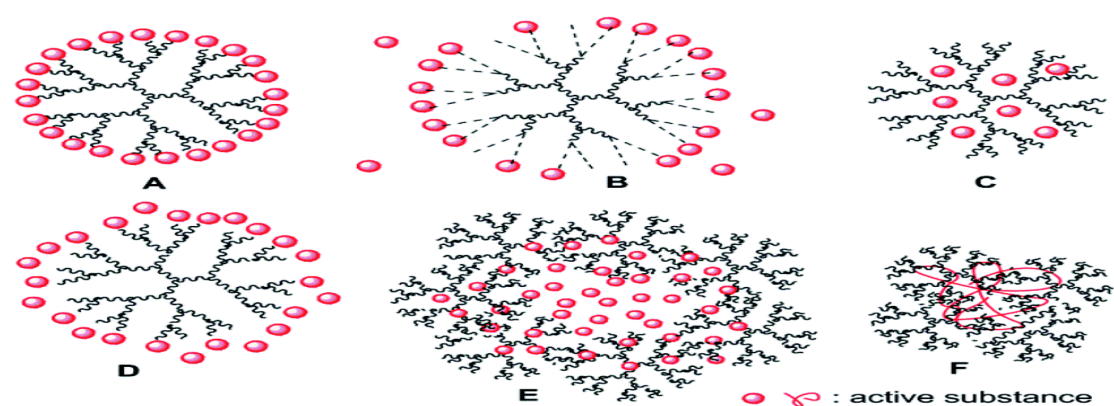

Fig.5. Drug delivery using dendrimers [11]

\subsection{Water Filtration technique:}

Carbon nanotubes based films are utilized for water desalination and nanoscale sensors to analyze toxins in water framework. The course of water filtration utilizing carbon nanotubes is displayed in Figure 6.Nanoscale titanium dioxide is the other nanoscale material that can possibly channel and purge water framework and it is likewise utilized in sunscreen to kill microorganisms [11].

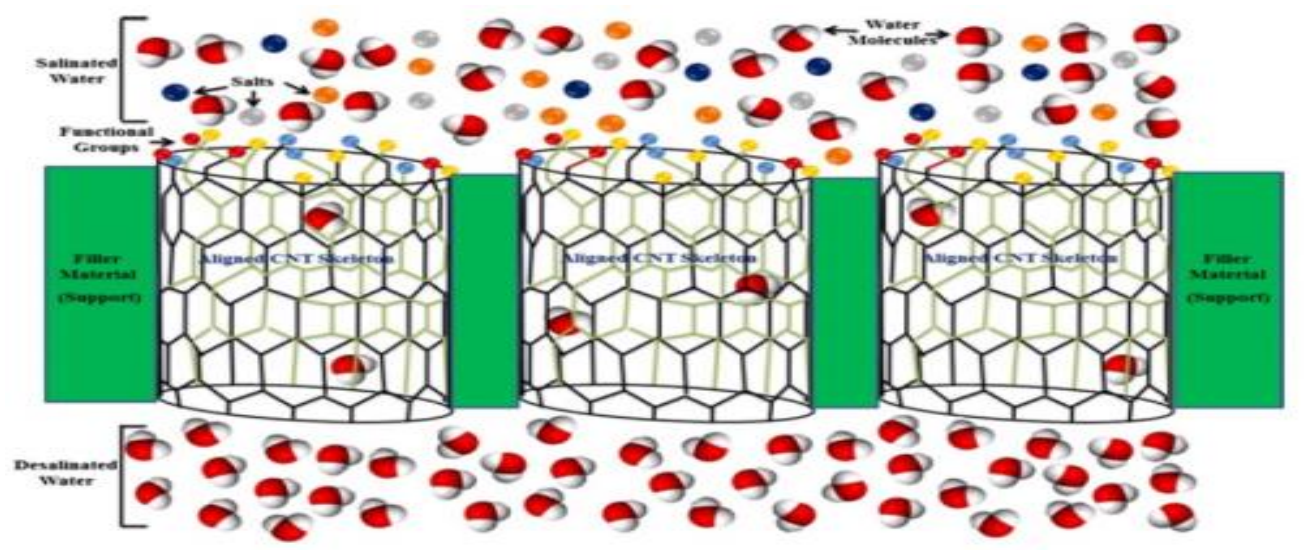

Fig.6. Water filtration technique [8] 


\section{Application of Nanotechnology:}

\subsection{Sustainable Energy Application:}

The trouble of satisfying the world $\mathrm{se}$ energy need is compounded by the developing need to secure our current circumstance. Numerous researchers are investigating ways of growing spotless, reasonable, and sustainable power sources, alongside means to diminish energy utilization and decrease harmfulness troubles on the climate. Model sun powered chargers fusing nanotechnology are more effective than standard plans in changing daylight over to power, promising modest sun oriented force later on. Nanostructured sunlight based cells as of now are less expensive to produce and simpler to introduce, since they can utilize print-like assembling processes and can be made in adaptable rolls instead of discrete boards.

Nanotechnology is working on the productivity of fuel creation from typical and second rate crude oil materials through better catalysis, just as fuel utilization proficiency in vehicles and force plants through higher-effectiveness burning and diminished grating [13]. Nanobioengineering of proteins is meaning to empower change of cellulose into ethanol for fuel, from wood chips, corn stalks (in addition to the pieces, as today), and unfertilized enduring grasses [14]. Figure 7 shows some use of nanotechnology. Nanotechnology is as of now being utilized in various new sorts of batteries that are less combustible, quicker charging, more effective, lighter weight, and that have a more powerful thickness and hold electrical charge longer harmless creation process [15-17]. Nanostructured materials are being sought after to significantly improvehydrogen layer and capacity materials and the impetuses really should have understood energy units for elective transportation advancements at diminished expense. Scientists are additionally attempting to foster a protected, lightweight hydrogen gas tank. Different Nano science based choices are being sought after to change over squander heat in PCs, vehicles, homes, power plants, to usable electrical force $[18,19]$.

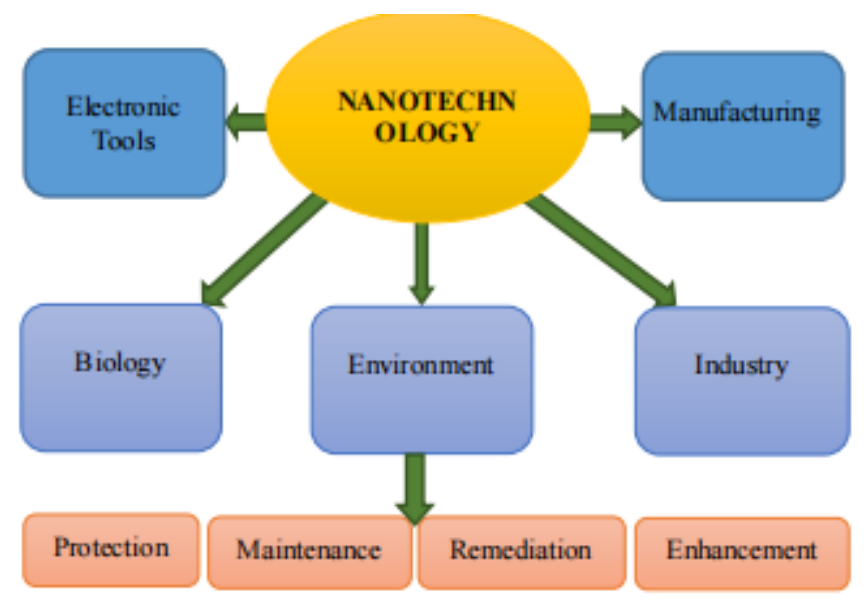

Fig. 7 Application of nanotechnology in science and environmental science.[19] 
To control versatile electronic gadgets, specialists are growing flimsy film sun based electric boards that can be fitted onto PC cases and adaptable piezoelectric nanowires woven into apparel to produce usable energy in a hurry from light, grinding, as well as body heat. Energy proficiency items are expanding in number and kindsof application. Notwithstanding those prominent above, they incorporate more proficient lighting frameworks for tremendously diminished energy utilization for enlightenment; lighter and more grounded vehicle suspension materials for the transportation area; lower energy utilization in cutting edge gadgets; lowgrinding nano-designed oils for a wide range of higher-effectiveness machine pinion wheels, siphons, and fans; light-responsive keen coatings for glass to supplement elective warming/cooling plans; and high-light-power, quick re-energizing lamps for crisis groups. Other than lighter vehicles and apparatus that requires less fuel, and elective fuel and energy sources, there are numerous eco-accommodating applications for nanotechnology, for example, materials that give clean water from contaminated water sources in both huge scope and versatile applications, and ones that recognize and tidy up ecological foreign substances. Nanotechnology could assist with addressing the requirement for reasonable, clean drinking water through fast, minimal expense location of contaminations in and filtration and purging of water [20-22].

Nanoparticles will some time or another be utilized to clean modern water contaminations in ground water through synthetic responses that render them innocuous, at much lower cost than techniques that require siphoning the water out of the ground for treatment. Nanotechnology has the genuine potential to alter a wide cluster of clinical and biotechnology apparatuses and systems with the goal that they are more customized, convenient, less expensive, more secure, and simpler to direct. The following are a few instances of significant advances here. Nanotechnology has been utilized in the early finding of atherosclerosis, or the development of plaque in courses. Specialists have fostered an imaging innovation to quantify the measure of a neutralizer nanoparticle complex that gathers explicitly in plaque. Clinical researchers can screen the improvement of plaque just as its vanishing following treatment. Gold nanoparticles can be utilized to identify beginning phase Alzheimerees illness [23-25].

\subsection{Sensors and Medicine Application:}

Atomic imaging for the early recognition where delicate biosensors developed of nanoscale parts (e.g., nano-cantilevers, nanowires, and nano-channels) can perceive hereditary and sub-atomic occasions and have detailing capacities, consequently offering the possibility to distinguish uncommon sub-atomic signs related with threat. Multifunctional therapeutics where a nanoparticle fills in as a stage to work with its particular focusing to disease cells and conveyance of an intense therapy, limiting the danger to typical tissues. Exploration empowering influences, for example, microfluidic chip-based Nano labs fit for observing and controlling individualcells and Nano scale tests to follow the developments of cells and individual particles as they move about in their surroundings. Nano-bio frameworks, Medical, and Health Applications. 
Nanotechnology has the genuine potential to change a wide cluster of clinical and systems with the goal that they are more customized, versatile, less expensive, more secure, and simpler to manage. The following are a few instances of significant advances there [26-31].

Quantum spots are semiconducting nanocrystals that can improve natural imaging for clinical diagnostics. When enlightened with bright light, they emanate a wide range of brilliant tones that can be utilized to find and distinguish explicit sorts of cells and organic exercises. These precious stones offer optical up to multiple times better compared to ordinary colors utilized in numerous natural tests, like MRIs, and render essentially more data. Multifunctional therapeutics where a nanoparticle fills in as a stage to work with its particular focusing to malignant growth cells and conveyance of a strong treatment, limiting the danger to typical tissues [32-35].

Exploration empowering agents, for example, microfluidic chip-based nano-labs equipped for observing and controlling individual cells and Nano scale tests to follow the developments of cells and individual atoms as they move about in their surroundings. Examination is in progress to utilize nanotechnology to prod the development of nerve cells, e.g., in harmed spinal line or synapses. In one technique, a nanostructured gel occupies the space between existing cells and urges new cells to develop. There is early work on this in the optical nerves of hamsters. Another technique is investigating utilization of Nano filaments to recover harmed spinal nerves in mice [36-40].

\subsection{Future Transportation Applications:}

Nano-designing of steel, cement, black-top, and other cementations materials, and their reused structures, offers extraordinary guarantee as far as working on the presentation, strength, and life span of thruway and transportation foundation parts while diminishing their expense. New frameworks might join inventive capacities into customary foundation materials, like the capacity to create or communicate energy. Nano scale sensors and gadgets might give savvy consistent underlying checking of the condition and execution of extensions, burrows, rails, stopping constructions, and asphalts over the long run. Nano scale sensors and gadgets may likewise uphold an improved transportation framework that can speak with vehicle-based frameworks to assist drivers with keeping up with path position, avoidcollisions, change head out courses to circumnavigate clog, and other such exercises [41-50]

Examination is in progress to utilize nanotechnology to spike the development of nerve cells, e.g., in harmed spinal rope or synapses. In one strategy, a nanostructured gel occupies the space between existing cells and urges new cells to develop. There is early work on this in the optical nerves of hamsters. Another strategy is investigating utilization of Nano filaments to recover harmed spinal nerves in mice [51-57].

\subsection{Nanotechnology for Environmental Protection:}

Over the most recent couple of many years, profoundly poisonous natural mixtures have been incorporated and delivered into the climate to be utilized straightforwardly or by implication over a significant stretch. Among a portion of these components are pesticides, powers, 
polycyclic fragrant hydrocarbons (PAHs), and polychlorinated biphenyls (PCBs) [58]. Some consolidated synthetic mixtures oppose profoundly against biodegradation by means of local verdure in examination with natural substances effectively corrupted through presentation into the climate. In this way, perilous substance compounds have been one of the most significant issues in the contemporary world. The administration of polluted soil and ground water is a significant natural concern. The presence of raised centralizations of a wide scope of pollutants in soils, silt and surface-and ground waters, influences the wellbeing of millions of individuals overall [59]. Current tidy up innovation isn't fundamentally and financially satisfactory to tackle all of today ${ }^{e e}$ s tidy up needs.

Nanotechnology is one of the main patterns in science and saw as one of the vital innovations of the current century [60]. Nanotechnology could be an integral asset in managing contamination remediation. A few examinations show that joining nanoparticles with regular treatment could expand the effectiveness of pollutants evacuation, like natural materials. In Zhang ${ }^{\text {ee }}$ report [61], nano scale iron particles are extremely viable for the change and detoxification of a wide assortment of normal natural impurities, like chlorinated natural solvents, organochlorine pesticides, and PCBs. Nanoparticles stay receptive towards toxins in soil and water for broadened timeframes and fast in situ responses have been seen with TCE decrease up to almost $100 \%$ in a couple of days after the nanoparticle infusion. Numerous scientists have shown that designed nanoparticles like $\mathrm{TiO}_{2}$ andZnO, carbon nanotube, metallicnanoparticles (e.g., iron, nickel) attractive nanoparticles and amphiphilic polyurethane nanoparticles could be valuable for remediation and treatment of tainted water, soil or air.

Use of nanotechnology in natural science is sorted into four sections: remediation, insurance, support, and upgrade. Among these four, remediation is known as the most fast developing class, assurance and support make the fundamental piece of nanotechnology application in ecological science, while natural improvement addresses the littlest piece of nanotechnology application classifications. Nanoparticles can be used in air and water treatment, mesoporous components for green science, synergist applications and ecological atomic science. Alongside diminishing the size of the particles, they gain new substance, electronic and actual properties. Benefits incorporate further developed adsorption and one of a kind synergist properties that can speed up oxidation or decrease responses with various foreign substances for molecule that are under 10 $\mathrm{nm}$ [62]. Nanoscale materials have been at various defiled destinations with starter reports of accomplishment. Nanotechnology is likewise ready to further develop the climate through introducing compelling control and forestalling of defilement. For ecological treatment, various executions of nanotechnology have been effectively carried out at the research facility scale. Nonetheless, for the most part these applications need affirmation of their adequacy and security in the field. Customary remediation innovations have demonstrated bound adequacy in decrease of the convergence of pollutions in air, water, and soil. As indicated by Boehm [63] 
nanomaterials can act all the more astoundingly and powerfully as filtration media in correlation with greater particles with similar synthetic substances [64].

\subsection{Remedial Technology by Nanomaterials:}

Overall nanoparticles are more modest than 100 nanometers contain 20-15000 particles, and exist in a domain that rides the quantum and Newtonian scales. They can be created from various materials in various shapes, for example, circles, poles, wires and cylinders. Nanotechnology is an arising trend setting innovation for taking care of ecological issues. The outcome in imaginative nanotechnology advancement, for example, nano sorbent, nano impetus, bioactive nanoparticles, nano organized synergist layers and nanoparticle improved filtration, gives remarkable freedom in changing all exorbitant and restricted traditional water medicines. There are two significant properties that makes nanoparticles appealing: initially, nanoparticles are minuscule in size $(1-100 \mathrm{~nm})$, which gives higher surface region per unit mass contrasted with the mediaproduced by regular strategies. Furthermore, the sub-atomic level controls continued in nano molecule creation works with consolidation of wanted primary and practical qualities (e.g., surface region, pore size, design and surface utilitarian gatherings) on the adsorption surface.

Yang (1999) noticed initiated carbons were used to a great extent as customary adsorbents in European nations for the expulsion of dioxins from the vaporous emanations of waste cremation. Additionally, as per Mahdavian [65] the expulsion of synthetic defilements from a contaminated region is a vital stage toward achieving the point of natural remediation. Many investigations have zeroed in on more successful materials in adsorbing contaminations that are broadly different. Beforehand, montmorillonite and bentonites were utilized to adsorb oils spills since they were known as the littlest particles and could adsorb huge measures of synthetic compounds.

Bowman et al. [66] shows that for the expulsion of tainting, the interaction can be partitioned into two principle gatherings. The principal cycle as a sorption in which, the foreign substance is eliminated from arrangement because of the sorption of the pollutant to the medium. Without a doubt, the course of sorption is really quick, yet at long last the greatest limit of the mixtures ought to be supplanted by new materials. A substitute sort of interaction is debasement or change materials. In a perfect world, the toxin will be changed to a non-poisonous compound subsequent to interacting with the material. Debasement response will in general be actively sluggish comparative with sorption responses, and thick material beds might be important to give the necessary the home time. By and large, the utilization of nanomaterials for natural remediation thinks about separating the poisons into non-poisonous components and retaining the contaminations for delivering the insoluble compound materials to diminish relocation. Liu et al. [67] revealed that MWNT was a viable adsorbent for evacuation of chlorinated sweet-smelling compounds (counting PCBs) from protecting oil. Figure 8 show the plan of the age of covalently bound surface acidic gatherings on MWNT.

Different uses of nanotechnologies for natural remediation have been effectively exhibited at the research center scale be that as it may, in most of cases, these still require confirmation of their 
viability and wellbeing in the field. Different treatment methods and cycles have been utilized to eliminate the toxins from polluted soil and water. Among every one of the methodologies proposed, adsorption is perhaps the most well known method and is as of now considered as a powerful, proficient, and financial technique for soil and water filtration [67].

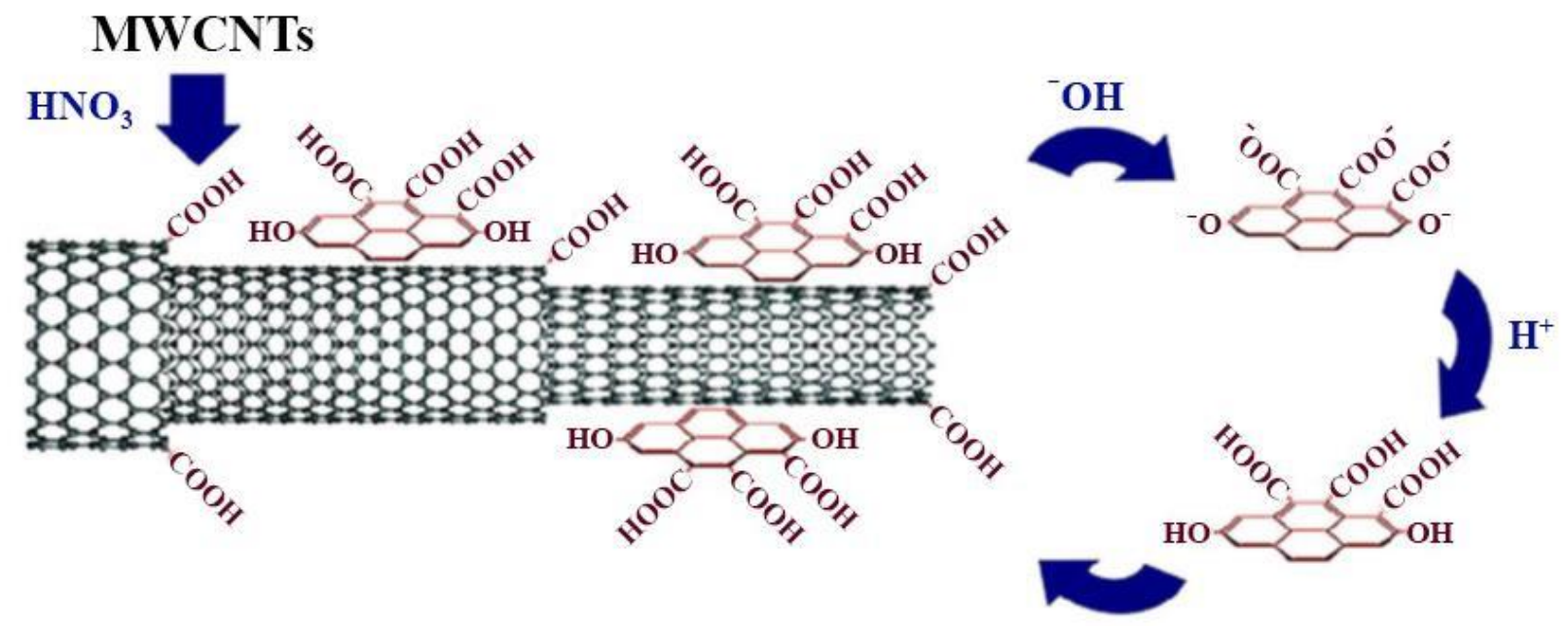

Fig. 8. Simplified scheme of the generation of covalently bound surface acidic groups[67]

\subsection{Application of Nanotechnology in Remediation:}

Nanomaterials have additionally been utilized to remediate debased groundwater and subsurface source spaces of defilement at unsafe waste destinations. Early treatment solutions for groundwater pollution were principally siphon and-treat tasks. As a result of the somewhat significant expense and regularly extended working periods for these cures, the utilization of in situ treatment advances is expanding.

Since the mid-1990s, site project supervisors enjoy taken benefit of the properties of metallic substances, for example, essential iron to corrupt chlorinated dissolvable tufts in groundwater. One illustration of an in situ treatment innovation for chlorinated dissolvable crest is the establishment of a channel loaded up with macroscale zero valent iron to shape a penetrable receptive hindrance (PRB) [68]. Late examination demonstrates that nanoscale zerovalent iron (nZVI) may demonstrate more successful and less exorbitant than macroscale ZVI under comparable natural conditions. For instance, in research center and field-scale examines, nZVI particles have been displayed to corrupt trichloroethene (TCE), a typical impurity at Superfund locales, more quickly and totally than bigger ZVI particles. Additionally, nZVI can be infused straightforwardly into a defiled spring, dispensing with the need to burrow a channel and introduce a PRB. Exploration shows that infusing nZVI particles into regions inside springs that 
are wellsprings of chlorinated hydrocarbon pollution might result in quicker, more viable groundwater cleanups than customary siphon and-treat strategies or PRBs. Exploration shows that nanoparticles like nZVI, bi-metallic nanoscale particles (BNPs), and emulsified zero-valent iron (EZVI) may synthetically diminish the accompanying foreign substances viably: perchloroethylene (PCE), TCE, cis-1, 2-dichloroethylene (c-DCE), vinyl chloride (VC), and 1-11-tetrachloroethane (TCA), alongside polychlorinated biphenyls (PCBs), halogenated aromatics, nitroaromatics, and metals like arsenic or chromium. Two of the significant debasement responses forchlorinated solvents are reductive dechlorination and beta disposal. Beta disposal, which happens most habitually when the pollutant comes into direct contact with the iron, follows the pathway. Reductive dechlorination, which happens under the lessening conditions fostered by nZVI in groundwater, follows the pathway of $\mathrm{PCE} \rightarrow \mathrm{TCE} \rightarrow \mathrm{DCE} \rightarrow \mathrm{VC} \rightarrow$ ethane [69].

Nanoparticles can be exceptionally receptive because of their enormous surface region to volume proportion and the presence of a more prominent number of responsive locales. This takes into account expanded contact with toxins, accordingly bringing about fast decrease of foreign substance fixations. In view of their moment size, nanoparticles may plague tiny spaces in the subsurface and stay suspended in groundwater, which would permit the particles to travel farther than full scale estimated particles and accomplish more extensive dispersion. Nonetheless, as examined in the „Limitations ${ }^{\text {ee }}$ area, exposed iron nanoparticles may not travel exceptionally a long way from the infusion point. Note that there is changeability among iron nanoparticles, regardless of whether they have a similar synthetic sythesis [67]. The properties of particles like reactivity, versatility, and time span of usability can differ contingent upon the assembling system or the seller giving the molecule [67].

\subsection{In Situ Application of Nanoparticles:}

The technique for application for nanoparticles is generally site-explicit and is reliant upon the sort of geography found in the treatment zone and the structure in which the nanoparticles will be infused. The most immediate course of infusion uses existing observing wells, piezometers, or infusion wells. Distribution is a procedure that includes infusing nanoparticles in up slope wells while down angle wells extricate groundwater. The separated groundwater is blended in with extra nanoparticles and once again infused in the infusion well. The wells keep the water in the spring in touch with the nZVI, and furthermore keep the bigger agglomerated iron particles from settling out, permitting ceaseless contact with the pollutant.

Exploration is progressing into strategies for infusion that will permit nanoparticles to more readily keep up with their reactivity and increment their admittance to obstinate impurities by accomplishing more extensive conveyance in the subsurface. Making nZVI on location decreases the measure of oxidation the iron goes through, subsequently diminishing misfortune in reactivity. Scientists in green science have effectively made nZVI in soil segments utilizing a wide scope of plant phenols, which, as per the specialists, permits more noteworthy admittance to the impurity and makes less risky waste in the assembling system [70]. 
Site-explicit conditions like the site area and design, geologic conditions, centralization of toxins, and sorts of impurities might restrict the viability of nanoparticles. For instance, the examination directed for this reality sheet archives just two locales that have utilized nanoparticles in broken bedrock, albeit a few pilot studies have been embraced. The $\mathrm{pH}$ of the subsurface may likewise restrict the viability of nanoparticles in light of the fact that the sorption strength, agglomeration, and portability of the particles are totally influenced by the $\mathrm{pH}$ of the groundwater [68]. The ionic strength and sorts of cations in the groundwater, just as the compound and actual attributes of the spring materials, additionally influence the agglomeration and development of iron nanoparticles [70].

\subsection{Application of Nanotechnology in Food and Agriculture:}

The current worldwide populace is almost 6 billion with half living in Asia. An enormous extent of those living in agricultural nations face every day food deficiencies because of ecological effects or political shakiness, while in the created world there is a food excess. For agricultural nations, the drive is to foster dry season and vermin safe harvests, which additionally expand yield. In created nations, the food business is driven by buyer request which is presently for fresher and better staples. This is large business, for instance the food business in the UK is blasting with a yearly development pace of $5.2 \%$ and the interest for new food has expanded by $10 \%$ over the most recent couple of years. The capability of nanotechnology to change the medical services, material, materials. Data and correspondence innovation, and energy areas has been widely acclaimed. Indeed, a few items empowered by nanotechnology are now on the lookout, like antibacterial dressings, straightforward sunscreen moisturizers, smudge safe textures, scratch free paints for vehicles, and self-cleaning windows. The utilization of nanotechnology to the agrarian and food businesses was first tended to by a United States Department of Agriculture guide distributed in September 2003. The forecast is that nanotechnology will change the whole food industry, changing the manner in which food is delivered, handled, bundled, shipped, and devoured. This short report will audit the vital parts of these changes, featuring flow research in the agri food industry and what future effects these may have.

The EU ${ }^{e e}$ s vision is of a "information based economy" and as a component of this, it intends to boost the capability of biotechnology to help EU economy, society and the climate. There are new difficulties in this area including a developing interest for solid, safe food; an expanding hazard of infection; and dangers to agrarian and fishery creation from changing climate designs. Be that as it may, making a bio economy is a difficult and complex interaction involvingthe assembly of various parts of science.

Nanotechnology can possibly reform the rural and food industry with new apparatuses for the sub-atomic treatment of infections, quick sickness discovery, improving the capacity of plants to retain supplements and so forth, Smart sensors and shrewd conveyance frameworks will help the agrarian business battle infections and other harvest microbes. Sooner rather than later nanostructured impetuses will be accessible which will build the effectiveness of pesticides and 
herbicides, permitting lower dosages to be utilized. Nanotechnology will likewise secure the climate by implication using elective (environmentally friendly power) supplies, and channels or impetuses to decrease contamination and tidy up existing poisons. A rural technique generally utilized in the USA, Europe and Japan, which effectively uses current innovation for crop the executives, is called Controlled Environment Agriculture (CEA). CEA is a high level and escalated type of hydroponically-based farming. Plants are developed inside a controlled climate with the goal that green practices can be streamlined. The electronic framework screens and manages restricted conditions like fields of yields. CEA innovation, as it exists today, gives an amazing stage to the acquaintance of nanotechnology with farming. With a large number of the observing and control frameworks currently set up, nano mechanical gadgets for CEA that give "exploring" capacities could colossally work on the growere s capacity to decide the best season of reap for the yield, the imperativeness of the harvest, and food security issues, like microbial or synthetic pollution.

The utilization of pesticides expanded in the second $50 \%$ of the twentieth century with DDT becoming one of the best and inescapable all through the world. Be that as it may, large numbers of these pesticides, including DDT were subsequently observed to be profoundly harmful, influencing human and creature wellbeing and thus entire environments. As an outcome, they were prohibited. To keep up with crop yields, Integrated Pest Management frameworks, which blend customary techniques for crop revolution in with natural irritation control techniques, are becoming well known and carried out in numerous nations, like Tunisia and India. Later on, nanoscale gadgets with novel properties could be utilized to make farming frameworks "shrewd". For instance, gadgets could be utilized to distinguish plant medical problems before these become apparent to the rancher. Such gadgets might be fit for reacting to various circumstances by making a proper healing move. If not, they will make the rancher aware of the issue.

Along these lines, savvy gadgets will go about as both a preventive and an early admonition framework. Such gadgets could be utilized to convey synthetics in a controlled and designated way similarly as nano-medication has suggestions for drug conveyance in people. Nanomedicine advancements are presently starting to permit us to treat various illnesses like disease in creatures with high accuracy, and designated conveyance (to explicit tissues and organs) has become profoundly fruitful. Innovations, for example, embodiment and controlled delivery techniques, have upset the utilization of pesticides and herbicides. Many organizations make plans which contain nanoparticles inside the $100-250 \mathrm{~nm}$ size range that can break down in water more successfully than existing ones (in this manner expanding their movement). Different organizations utilize suspensions of nanoscale particles (nano-emulsions), which can be either water or oil-based and contain uniform suspensions of pesticidal or herbicidal nanoparticles in the scope of 200-400 nm. These can be effortlessly consolidated in different media like gels, creams, fluids and so forth, and have various applications for safeguard measures, treatment or conservation of the gathered item.

New examination likewise means to make plants use water, pesticides and manures all the more effectively, to diminish contamination and to make farming all the more harmless to the 
ecosystem. Horticulture is the foundation of most agricultural nations, with over $60 \%$ of the populace dependent on it for their occupation. Just as creating further developed frameworks for observing natural conditions and conveying supplements or pesticides as suitable, nanotechnology can improve our comprehension of the science of various harvests and along these lines possibly upgrade yields or healthy benefits. What's more, it can offer courses to added esteem crops or natural remediation.

Molecule cultivating is one such model, which yields nanoparticles for modern use by developing plants in characterized soils. For instance, research has shown that horse feed plants filled in gold rich soil, ingest gold nanoparticles through their foundations and gather these in their tissues. The gold nanoparticles can be precisely isolated from the plant tissue following harvest. Nanotechnology can likewise be utilized to clean ground water. The US organization Argonide is utilizing $2 \mathrm{~nm}$ measurement aluminum oxide nano-filaments (Nano-Ceram) as a water purifier. Channels produced using these strands can eliminate infections, microbes and protozoan growths from water. Comparable tasks are occurring somewhere else, especially in non-industrial nations like India and South Africa. The German synthetic gathering BASF ${ }^{e e}$ future business store has dedicated a huge extent of its 105 million USD nanotechnology research asset to water cleaning procedures.

Examination at Lehigh University in the US shows that a ultra fine, nanoscale powder produced using iron can be utilized as a powerful instrument for tidying up sullied soil and groundwater-a trillion-dollar issue that envelops in excess of 1000 still-untreated Superfund destinations (uncontrolled or deserted where dangerous waste is situated) in the United States, a few 150,000 underground storage tank releases, and a huge number oflandfills, abandoned mines, and industrial sites. The iron nanoparticles catalyze the oxidation and breakdown of natural pollutants, for example, trichloroethene, carbon tetra-chloride, dioxins, and PCBs to more straightforward carbon intensifies which are significantly less poisonous. This could prepare for a nano-hydroponics, which would be gainful for countless ranchers across the world. Other exploration at the Center for Biological and Natural Nanotechnology (CBEN) has shown that nanoscale iron oxide particles are amazingly successful at restricting and eliminating arsenic from groundwater (something which influences the water supply of millions of individuals in the creating scene, and for which there is no viable existing arrangement). It has been contended that nanotechnology holds the possibility to dispense with the idea of waste and contamination [71]. In a more humble vein it has been recommended that nanotechnology vows to radically cut asset utilization and contamination, will unequivocally decrease costs for reasonable converters of energy, for example, sunlight based cells and will make significantly better reusing and detoxification innovation conceivable. Nanotechnology has likewise been contended to take into account more prominent selectivity in substance responses, and to add to further developed energy productivity and to toxics decrease [71].

In any case, the rise of nanotechnology has additionally started banter about the dangers of ultrafine particles [72]. This writer presently focuses on perils of nanoparticles as they are right now utilized in or examined for use underway and items and on the issue of how can be dealt 
with limit the related dangers. Numerous current or imminent applications utilize fixed nanoparticles and are consequently not intrinsically dispersive. A longstanding model thereof is the utilization of carbon dark for printing and in the creation of tires. More up to date applications incorporate coatings, materials, pottery, films, composite materials, glass items, prosthetic inserts, hostile to static bundling, cutting instruments, modern impetuses, and an assortment of electric and electronic gadgets including showcases, batteries and energy components. Different employments of nanoparticles are intrinsically dispersive or „free (Royal Society). These incorporate medications, individual consideration items like beauty care products, quantum specks and some pilot applications in natural remediation [73]. Aside from fabricated nanoparticles, there are additionally ultra fine particles that are produced in accidental ways. These incorporate particles starting in the ignition of fills, for example ultrafineparticles radiated by diesel filled vehicles [74] in purifying cycles of metals, warming of polymers [75] or singing food varieties [76] and are likewise called non-produced nanoparticles. The vast majority of the produced nanoparticles as of now utilized are produced using metal oxides, silicon and carbon [77]. So far the greater part ofnanosized supported medication conveyance frameworks are lipid, liposomal and poly ethylene glycol-based [78]. Possible openness to made nanoparticles may increment significantly in the future [79-89].

\section{Conclusions:}

Nanotechnology is the study of minuscule particles. The nanotechnology imagines a world wherein new items are planned at the nuclear and atomic level; give sensible, savvy techniques for lashing sustainable power sources and keeping the climate clean. These days, a considerable lot of researchers and designers are discovering better approaches to utilize nanotechnology to work on the world. There are various utilization of nanotechnology including hardware, science, substance designing and advanced mechanics gadgets. By the assistance of nanotechnology, specialists identifying infection at its most punctual stages and treating ailment like coronary illness, disease and diabetes with more viable and more secure medications. Scientists additionally picture new advances for ensuring both the regular folks and military powers from traditional and substance weapons. In spite of the fact that there are many exploration challenges ahead, nanotechnology as of now is creating a huge scope of good materials and highlighting improvement in many fields. It has opened logical Inquiry to the degree of nanoparticles and offers a universe of new chances.

\section{Abbreviations:}

DNA: Deoxyribonucleic acid; PAHs :Polycyclic fragrant hydrocarbons; PCBs:Polychlorinated biphenyls ; PRB: Penetrable receptive hindrance; nZVI: Nanoscale zerovalent iron; TCE: Trichloroethene; BNPs: bi-metallic nanoscale particles; PCE:perchloroethylene; c-DCE: cis-1, 2-dichloroethylene ; VC :vinyl chloride TCA: 1-1-1-tetrachloroethane; CEA:Controlled Environment Agriculture; USA: United State of America; DDT: CBEN:Center for Biological and Natural Nanotechnology. 


\section{References:}

[1] Sakhare D.T. (2021), Nanotechnology and Their Applications in Science and Technology Review,International Journal of Advanced Science and Engineering. Vol.8 No.1 :2106-2118.

[2] Centre Responsible For Nanotechnology, http://www.crnano.org/whatis.html.

[3] D.Bhattacharyyal et.al., "Nanotechnology, Big things from a Tiny World: a Review", International Journal of $u$ - and e-Service, Science and Technology, Vol. 2, No. 3, September, 2009.

[4] Nanotechnology: A Brief Literature Review M.Ellin Doyle, Ph.D Food Research Institute, University of Wisconsin-Madison, Madison, WI 53706.

[5] Lusk, Mark T., and Lincoln D. Carr. "Nanoengineering defect structures on graphene." Physical review letters 100.17 (2008): 175503.

[6] "Environment and Green Nano - Topics - Nanotechnology Project". Retrieved 11 September 2011

[7] National Nanotechnology Initiative. http://www.nano.gov

[8] "Nanotechnology in water treatment". Retrieved 3 November 2013.

[9] http://faculty.tamucommerce.edu/dyeager/599/newtechnologyparti_files/v3_slide0205.htm C ontemporary Tech

[10] http://www.questia.com/read/113729011?title=7\%3A+Wet+Nanotech; Book by William Illsey Atkinson "Nanocosm: Nanotechnology and the Big Changes Coming from the Inconceivably Small" (c) 2003.

[11] http://www.nottingham.ac.uk/physics/research/nano/pdfs/N15ND05.pdf Nanotechnology.

[12] Nanoelectronics:Nanotechnology in electronics. http://www.understandingnano.com

[13] Low J, Yu J, Ho, W. (2015). Graphene-Based Photocatalysts for CO2 Reduction to Solar Fuel. The journal of physical chemistry letters, 6(21): 4244- 4251.

[14] Chaturvedi S, and Dave PN (2014). Emerging applications of nanoscience. Paper presented at the Materials Science Forum, 152-159.

[15] Jalaja K, Naskar D, Kundu S.C, James NR. (2016). Potential of electrospun core-shell structured gelatin-chitosan nanofibers for biomedical applications. Carbohydrate polymers, vol. 136, 1098-1107.

[16] Najim M, Modi G, Mishra YK, Adelung R, Singh D, Agarwala V. (2015). Ultra-wide bandwidth with enhanced microwave absorption of electroless $N i-P$ coated tetrapod-shaped ZnO nano-and microstructures. Physical Chemistry Chemical Physics, 17(35): 2923-2933.

[17] Maine E, Thomas V, Bliemel M, Murira A, Utterback J. (2014). The emergence of the nanobiotechnology industry. Nature nanotechnology, 9(1): 12-15.

[18] Pratsinis SE. (2016). Overview-Nanoparticulate Dry (Flame) Synthesis \& Applications. UNE, 13-15.

[19] Sabet M, Hosseini S, Zamani A, Hosseini Z, Soleimani H. (2016). Application of Nanotechnology for Enhanced Oil Recovery: A Review. Paper presented at the Defect \& Diffusion Forum. 
[20] Rabbani MM, Ahmed I, Park SJ. (2016). Application of Nanotechnology to Remediate Contaminated Soils Environmental Remediation Technologies for Metal-Contaminated Soils. Springer, 219-229.

[21] Sobolev K, Shah SP. (2015). Nanotechnology in Construction. Proceedings of NICOM5, Springer.

[22] Mishra Y, Chakravadhanula V, Hrkac V, Jebril S, Agarwal D, Mohapatra S, Adelung R. (2012).Crystal growth behaviour in Au-ZnO nanocomposite under different annealing environments and photo switch ability. Journal of Applied Physics. 112(6): 301-309.

[23] Fan W, Shi J, Bu W. (2016). Engineering Upconversion Nanoparticles for Multimodal Biomedical Imaging Guided Therapeutic Applications Advances in Nanotheranostics. Springer, 165-195.

[24] Sadeghi R, Ansari S, Uzun S, Bozkurt F, Gezer P, Karimi M, Kokini J. (2016). Nanobiotechlogy: Applications in Food Science and Engineering. UNE, 13-15.

[25] Tarafdar J, Sharma S, Raliya R. (2015). Nanotechnology: Interdisciplinary science of applications. African Journal of Biotechnology, 12(3): 65-72.

[26] George S. (2015). Nanomaterial Properties: Implications for Safe Medical Applications of Nanotechnology Nanotechnology in Endodontics, Springer, 45-69.

[27] Ng C. K, Mohanty A, \& Cao B. (2015). Biofilms in Bio-Nanotechnology. BioNanoparticles: Biosynthesis and Sustainable Biotechnological Implications, 83-100.

[28] Weiss PS. (2015). Where are the products of nanotechnology, Acs Nano, 9(4): 3397-33101.

[29] Yashveer S, Singh V, Kaswan V, Kaushik A, \& Tokas J. (2014). Green biotechnology, nanotechnology and bio-fortification: perspectives on novel environment-friendly crop improvement strategies. Biotechnology and Genetic Engineering Reviews, 30(2): 113-126.

[30] Schulte P, Geraci C, Murashov V, Kuempel E, Zumwalde, R., Castranova, V., Martinez, K. (2014). "Occupational safety and health criteria for responsible development of nanotechnology”. Journal of Nanoparticle Research, vol. 16(1): pp. 1- 17, 2014.

[31] Boisseau P, Loubaton B. (2011). Nanomedicine, nanotechnology in medicine. Comptes Rendus Physique, 12(7): 620-636.

[32]Adam M, Wang Z, Dubavik A, Stachowski G.M, Meerbach C, Soran-Erdem Z, Eychmüller A. (2015). Semiconductor Nanocrystals: Liquid-Liquid Diffusion-Assisted Crystallization: A Fast and Versatile Approach Toward High Quality Mixed Quantum Dot-Salt Crystals (Adv. Funct. Mater. 18/2015). Advanced Functional Materials, 25(18): 2783-2783.

[33] Milliron DJ (2014). Quantum dot solar cells: The surface plays a core role. Nature materials, 13(8): 772-773.

[34] Peterson MD, Cass LC, Harris RD, Edme K, Sung K, \& Weiss EA. (2014). The role of ligands in determining the exciton relaxation dynamics in semiconductor quantum dots. Annual review of physical chemistry, 65: 317-339.

[35] Schnitzenbaumer KJ, Dukovic G. (2014). Chalcogenide Ligand Passivated CdTe Quantum Dots Can Be Treated as Core/Shell Semiconductor Nanostructures. The Journal of Physical Chemistry C, 118(48): 28170-28178. 
[36] Liu X, Pi B, Wang H, Wang XM (2015). Self assembling peptide nanofiber hydrogels for central nervous system regeneration. Frontiers of Materials Science, 9(1): 1-13.

[37] Raspa A, Pugliese R, Maleki M, \& Gelain F. (2015). Recent therapeutic approaches for spinal cord injury. Biotechnology and bioengineering.

[38] Tam RY, Fuehrmann T, Mitrousis N, Shoichet MS (2014). Regenerative therapies for central nervous system diseases: a biomaterials approach. Neuro psychopharmacology, 39(1): 169-188.

[39] Guo JS, Qian CH, Ling EA, Zeng YS (2014). Nanofiber Scaffolds for Treatment of Spinal Cord Injury. Current medicinal chemistry, 21(37): 4282-4289.

[40] Kim D, Wu X, Young AT, Haynes CL (2014). Microfluidics-based in Vivo mimetic systems for the study of cellular biology. Accounts of chemical research, 47(4): 1165-1173.

[41] Agzenai Y, Pozuelo J, Sanz J, Perez I, Baselga J. (2015). Advanced Self-Healing Asphalt Composites in the Pavement Performance Field: Mechanisms at the Nano Level and New Repairing Methodologies. Recent patents on nanotechnology, 9(1): 43-50, 2015.

[42] Firoozi AA, Taha M.R, Firoozi AA, Khan TA. (2015). Effect of ultrasonic treatment on clay microfabric evaluation by atomic force microscopy. Measurement, 66: 244-252.

[43] Golestani B, Nam B.H, Nejad F.M, Fallah S. (2015). Nanoclay application to asphalt concrete: Characterization of polymer and linear nanocomposite-modified asphalt binder and mixture. Construction and Building Materials, 91: 32-38.

[44] Singh A, Sangita AS (2015). Overview of Nanotechnology in Road Engineering. Journal of Nano-and Electronic Physics, 7(2): 2014-2022.

[45] Sobolev K. (2015). Nanotechnology and Nano engineering of Construction Materials Nanotechnology in Construction, Springer, 3-13.

[46] De Nicola F, Castrucci P, Scarselli M, Nanni F, Cacciotti I, De Crescenzi M. (2015). Super-hydrophobic multi-walled carbon nanotube coatings for stainless steel. Nanotechnology, 26(14): 145-152.

[47] Chuah S, Pan Z, Sanjayan JG, Wang CM, Duan WH. (2014). Nano reinforced cement and concrete composites and new perspective from graphene oxide. Construction and Building Materials, 73: 113-124, 2014.

[48] Firoozi AA, Taha MR, Firoozi AA, Khan TA. (2014). Assessment of Nano-Zeolite on Soil Propertie. Australian Journal of Basic and Applied Sciences. 292-295.

[49]Wong S. (2014). An Overview of Nanotechnology in Building Materials. Canadian Young Scientist Journal, 14(2): 18-21.

[50] Yusoff NIM, Breem AAS, Alattug HN, Hamim A, Ahmad J. (2014). The effects of moisture susceptibility and ageing conditions on nano silica/polymer-modified asphalt mixtures. Construction and Building Materials, 72: 139-147.

[51] Qazi TH, Mooney DJ, Pumberger M, Geißler S, Duda GN (2015). Biomaterials based strategies for skeletal muscle tissue engineering: Existing technologies and future trends. Biomaterials, 53, 502-521. 
[52] Ahmadi M, Ahmadi L. (2013). European Patent Law Framework regarding Nanotechnology Applications in Stem Cells. Nanotech. L. \& Bus., 10: 65-72.

[53] Khan TA, Taha MR, Firoozi AA, Firoozi AA (2015). October. Strength tests of enzymetreated illite and black soil mixtures. In Proceedings of the Institution of Civil EngineersEngineering Sustainability, 169(5): 214-222. Thomas Telford Ltd.

[54] Parpura V, Verkhratsky A. (2013). Astrogliopathology: Could nanotechnology restore aberrant calcium signalling and pathological astroglial remodeling, Biochimica et Biophysica Acta (BBA)-Molecular Cell Research, 18(7): 1625-1631.

[55] Zhan X, Gao M, Jiang Y, Zhang W, Wong WM, Yuan Q, Zhang W. (2013). Nanofiber scaffolds facilitate functional regeneration of peripheral nerve injury. Nanomedicine: Nanotechnology, Biology and Medicine, 9(3): 305-315.

[56] Ehrhardt DW, Frommer WB (2012). New technologies for 21st century plant science. The Plant Cell, 24(2): 374-394.

[57] Jain KK (2012). Nanoneurology The handbook of Nanomedicine, Springer, 343-367. Nunes A, Al-Jamal KT, Kostarelos K. (2012). Therapeutics, imaging and toxicity of nanomaterials in the central nervous system. Journal of Controlled Release, 161(2): 290-306.

[58] Jones J, Parker D, Bridgwater J. (2007). Axial mixing in a ploughshare mixer, Powder technology, 178(2): 73-86.

[59] Pereira MFR, Soares SF, Órfão JJ, Figueiredo JL. (2003). Adsorption of dyes on activated carbons: influence of surface chemical groups, Carbon, 41(4): 811-821.

[60] Zhang WX, Elliot D.W. (2006). Applications of iron nanoparticles for groundwater remediation. Remediation, 16(2): 402-411.

[61] Rickerby DG Morrison M. (2007). Nanotechnology and the environment: A European perspective. Science and Technology of Advanced Materials, 8(1): 19- 24.

[62] Cosgun A, Fu R, Jiang W, Li J, Song J, Song X, Zeng H. (2015). Flexible quantum dot-PVA composites for white LEDs. Journal of Materials Chemistry C, 3(2): 257-264, 2015.

[63] Dang X, Hu H, Wang S, Hu S. (2015). Nanomaterials based electrochemical sensors for nitric oxide. Microchimica Acta, 182(3-4), 455-467.

[64] Yang R.T, Long R.Q, Padin J, Takahashi A, Takahashi T. (1999). Adsorbents for dioxins: a new technique for sorbent screening for low-volatile organics. Industrial \& Engineering Chemistry Research, 38(7): 2726-2731.

[65] Mahdavian L, Monajjemi M. (2010). Alcohol sensors based on SWNT as chemical sensors: Monte Carlo and Langevin dynamics simulation. Microelectronics Journal, 41: 142-149.

[66] Bowman RS. (2003). Applications of surfactant modified zeolites to environmental remediation. Microporous and Mesoporous Materials, 61(1): 43- 56.

[67] Liu X, Pi B, Wang H, Wang XM (2015). Self assembling peptide nanofiber hydrogels for central nervous system regeneration. Frontiers of Materials Science, 9(1): 1-13.

[68] Elliot DW. (2006). NZVI chemistry and treatment capabilities. Federal Remediation Technologies Roundtable (FRTR). Remediation technologies screening matrix and reference guide, Accessed September 25. 
[69] Phenrat T, Saleh N, Sirk K, Tilton R, Lowry GV. (2007). Aggregation and sedimentation of aqueous nanoiron dispersions. Environ Sc. Technol. 41(1): 284-290.

[70] Hart S.L, Milstein M.B. (2003). Creating sustainable value. Academy of Management Executive. 17: 172-180.

[71] Fryxell G.E, Lin Y, Fiskum S, Birnbaum J.C, Wu H. (2005). Actinide sequestration using self-assembled monolayers on mesoporous supports. Environ Sci Technol, 39: 1324-1331.

[72] Salata OV. (2004). Applications of nanoparticles in biology and medicine. Journal of Nano biotechnology; 2(3):16-22.

[73] Oberdorster G, Sharp Z, Atudorei V, Elders A, Gelein R, Kreyling W. (2004). Translocation of ultrafine particles to the brain. Inhalation Toxicology, 16:437-442.

[74] Oberdorster G. Toxicology of ultrafine particles; in vivo studies. (2000). Philosophical Transactions of the Royal Society London, 358:271-279.

[75] Wallace L.A, Emmerich S.J, Howard-Reed C. (2004). Source strengths of ultrafine and fine particles due to cooking with a gas stove. Environmental Science and Technology, 38: 230-241.

[76] Dreher K.L. (2004). Health and environmental impact of nanotechnology: toxicological assessment of manufactured nanoparticles. Toxicological Sciences, vol. 77: pp. 35-39.

[77] Allen T.M, Cullis P.M. (2004). Drug delivery systems: entering the mainstream. Science, 303: 181-188.

[78] Ahmed S, Ahmad M, Swami B.L, Ikram S. (2016). A review on plants extract mediated synthesis of silver nanoparticles for antimicrobial applications: a green expertise. Journal of Advanced Research, 7(1): 17- 28.

[79] Yetisen A.K, Qu H, Manbachi A, Butt H, Dokmeci M. R, Hinestroza J.P, Yun S.H. (2016). Nanotechnology in Textiles. Acs Nano.

[80] Wong M.H, Misra R, Giraldo J.P, Kwak S.Y, Son Y, Landry M.P., Strano M.S. (2016). Lipid Exchange Envelope Penetration (LEEP) of Nanoparticles for Plant Engineering: A Universal Localization Mechanism. Nano letters.

[81] Zhao H, Song J, Song X, Yan Z, Zeng H. (2015). Ag/white graphene foam for catalytic oxidation of methanol with high efficiency and stability. Journal of Materials Chemistry A, 3(12): 6679-6684.

[82] Firoozi A.A, Taha M.R, Firoozi A.A. Khan T.A. (2015). Effect of Ultrasonic Treatment on Clay Microfabric Evaluation by Atomic Force Microscopy”, Measurement, 66: 244-252.

Firoozi A.A, Taha M.R, Firoozi A.A. (2014). Nanotechnology in Civil Engineering. EJGE, 19: 4673-4682.

[83] Altairnano. (2014). http://www.altairnano.com/applications.html.

[84] Bohn L, Rick A, Myer A. O'Connor G. (2001). Soil Chemistry. Published by. Wiley. Technology \& Engineering.

[85] Cao J, Zhang W.X. (2006). Stabilization of chromium ore processing residue (COPR) with Nano scale iron particles. J Hazard Mater, 132(2-3): 213-219.

[86] Chen Y, Crittenden JC, Hackney S, Sutter L, Hand DW. (2005). Preparation of a novel $\mathrm{TiO}_{2}$-based p-n junction nanotube photo catalyst”. Environ Sci Technol, 39(5): 1201-1208. 
[87] Xu F, Shen Y, Sun L, Zeng H, Lu Y. (2011). Enhanced photocatalytic activity of hierarchical $\mathrm{ZnO}$ nanoplate-nanowire architecture as environmentallysafe and facilely recyclable photocatalyst. Nanoscale, 3(12): 5020-5025.

[88] Rao N.V, Rajasekhar M, Vijayalakshmi K, Vamshykrishna M. (2015). The Future of Civil Engineering with the Influence and Impact of Nanotechnology on Properties of Materials. Procedia Materials Science, 10: 111-115.

[89] Sirivitmaitrie C, Puppala A.J, Chikyala V, Saride S. Hoyos L.R. (2008). Combined lime and cement treatment of expansive soils with low to medium soluble sulfate levels, American Society of Civil Engineers, Proceedings of the Geo Congress, 646- 653. 